\title{
Sociología de la cruz en el Nuevo Testamento
}

\author{
Rafael Aguirre, \\ Universidad de Deusto, Bilbao, España, \\ Centro de Reflexión Teológica, San Salvador.
}

\section{Introducción}

Situándose en el ámbito de la sociología del conocimiento se ha intentado descubrir las relaciones entre lo que con más frecuencia se confiesa como símbolo central de la fe cristiana, la muerte y resurrección de Cristo, y la realidad social a que responde. W. A. Meeks descubre cuatro funciones sociales de este símbolo'. B. Holmberg ${ }^{2}$ considera que es tal la multifuncionalidad del símbolo que prácticamente no se puede establecer ninguna relación determinada con la realidad social.

En estas discusiones no se suele distinguir entre la afurmación de la muerte de Jesús y la mención concreta de la cruz; se pasa de la una a la otra como si fuesen meramente equivalentes, lo cual no es correcto.

De la muerte de Jesús se habla continuamente en la predicación cristiana primitiva, pero, en cambio, las menciones de la cruz son relativamente escasas. Mi propósito es presentar las funciones sociales que ejerce la afirmación de la cruz en el Nuevo Testamento. Lo hago de una forma sobria y concisa, cinéndome a los textos biblicos y dejando al lector el placer y el riesgo de explicitar las consecuencias hermenéuticas y las aplicaciones para el presente.

Sin duda, debe evitarse el establecer relaciones simples y unidireccionales entre una idea, un símbolo o una creencia y una realidad social; sus funciones sociales pueden ser normalmente diversas. Pero en el caso que nos ocupa pienso que el planteamiento de la sociología del conocimiento es singularmente fructuoso. En efecto, a la hora de buscar la relación con la realidad social no es lo mismo que se trate de un lenguaje metafísico, de un conjunto mítico de ideas o de la afirmación de un hecho histórico. Y para los autores y destinatarios del Nuevo Testamento, como para los primeros cristianos, la cruz era una indiscutible realidad histórica, que conllevaba necesariamente relación con la vida con- 
crela y terrestre de Jesús de Nazaret.

Dentro del Nuevo Testamento la cruz (sustantivo stauros y el verbo stauroô) aparece en relatos de los evangelios, con especial frecuencia en textos de origen marcano, y en las cartas, sobre todo en las de Pablo, concretamente en pasajes polémicos de Gálatas, Filipenses y 1Corintios?.

\section{Las funciones sociales de la cruz en las carlas de Pablo}

Podemos agruparlas en cuatro puntos.

2.1. La cruz es un principio de innovación, que proporciona una visión diferente de la realidad y fundamenta una manera alternativa de valorar y de comportarse. De este modo, la afirmación de la cruz recalca la identidad del propio grupo y su unidad interna. Es un lenguaje que no pretende establecer puentes con la cultura de su tiempo, sino que subraya con fuerza la contraposición con la sociedad.

1Corintios considera que en el origen de las discordias y disensiones está una valoración equivocada de la predicación, porque se realiza según las normas de la sabiduría de la cultura mundana. Parece que la brillante predicación de Apolo ha deslumbrado a los sectores de la comunidad, que son los responsables de las divisiones y con los que Pablo polemiza.

1Corintios presenta también una contraposición entre la "sabiduría de la palabra" y la "palabra de la cruz" (1, 17-18). La identidad de la comunidad no se funda en la vinculación con un personaje famoso, ni en la elocuencia, ni en la sabiduría. La cruz significa una inversión radical de la interpretación de la realidad. "Mientras los judíos piden signos y los griegos buscan sabiduría, nosotros predicamos a un Mesías crucificado, escándalo para los judios, necedad para los gentiles" (1, 22-23). Es la más vigorosa referencia a la historia de Jesús que hace Pablo. La cruz es un patibulo vergonzoso reservado para esclavos y rebeldes polílicos. Para los judíos, en virtud de Deuteronomio 21, 22-23, un crucificado es, además, un maldito de Dios. La fe cristiana tiene su punto de partida en la confesión de un Mesías crucificado. Es una insólica inversión del orden simbólico: "al Mesías Jesús hizo Dios para nosotros sabiduría, justicia, santificación y redención" $(1,30)$.

Para Pablo, el inesperado, impensable y paradójico hecho de que el Mesías haya experimentado una muerte maldita por la ley, la cruz, significa una novedad y una ruptura en la forma como se constituye y se relaciona con el mundo el pueblo de Dios.

Los "fuertes" de Corinto viven el símbolo de la resurección con entusiasmo, se creen ya resucitados y por encima de loda convención social. Esto crea problemas de tipo moral (capítulos 5 y 6) y de convivencia con los "débiles" (capi- 
uulos 8 al 10). Pablo da una interpretación diferente de la resurrección y con otra función social: es la resurrección del crucificado y sus efectos últimos son aún futuros (capítulo 15). La cruz invierte los valores vigentes y hace del débil punto de referencia del comportamiento de todos; por otra parte, como sus efectos últimos son aún futuros no podemos prescindir de los ritmos y de los condicionamientos de la realidad histórica.

En Corinto, la espiritualidad entusiasta es una aceptación, sublimada si se quiere, de los valores hegemónicos (sabiduria, poder, prestigio), que prende entre los cristianos bien siluados. Pero la cruz hace ver las cosas de otra manera. Es, paradójicamente, una sabiduría más prolunda, que ve el mundo desde el punto de vista de Dios $(2,14$ ss) y sólo es captable desde los tenidos por necios, débiles y plebeyos.

En Gálatas la referencia a Crisw crucificado se realiza para justificar la innovación de Pablo, la ruptura con la ley y la circuncisión, usos que quieren reintroducir en la comunidad los predicadores adversarios del apóstol. "¿Quién les fascinó a ustedes, a cuyos ojos fue presentado Jesucristo crucificado? Quiero saber de ustedes una sola cosa: ¿recibieron el Espíritu por las obras de la Ley o por la fe en la predicación?" (3, 1-5).

No hay forma más rotunda para subrayar la novedad cristiana que afirmar un dato histórico y, además, sumamente escandaloso, la realidad de un Mesías crucilicado.

Es una actitud en ruptura con la vigente en el judaísmo y que cuesta mantener. Por eso "los que quieren ser bien visios en lo humano les fuerzan a circuncidarse para evitar la persecución por la cruz de Cristo" $(6,12 ; 5,11)$.

En la carta a los Filipenses, el planteamiento es muy similar al de Gálatas. La cruz es el emblema de la novedad cristiana, libre de la circuncisión, contra los judaizantes. Los que quieren rejudaizar y vuelven a inculcar la circuncisión son "enemigos de la cruz de Cristo" $(3,18)$.

En 1Corintios, en Gálatas y en Filipenses, los problemas que se plantean son muy diferentes y, sin embargo, la reivindicación de la cruz tiene en estas cartas un fuerte carácter polémico y desempeña una función social análoga. En 1Corintios polemiza contra los de dentro de la comunidad, porque se asimilan en exceso a la cultura del ambiente; están deslumbrados por la "sabiduria", se identifican con la elocuencia, con la cultura, con el poder y con la estimación social, según las categorías de la sociedad helenística, lo que lleva a perder la novedad de la vida cristiana y crea disensiones y divisiones. En Gálatas y Fi. lipenses se trata de mantener una actitud novedosa contra quienes vienen de afuera y quieren que la comunidad retorne a los viejos usos judíos. En ambos casos se recurre a la cruz para promover actiudes socialmente crítcas, para crear una "realidad social" altemativa y mantener la unidad interma de la comunidad. 
2.2. La novedad cristiana establece una ruptura con el mundo $y$, por eso mismo, la alirmación de la cruz fortalece los vínculos internos de la comunidad. La cruz funda un comportamiento completamente diferente al hegemónico en el mundo, que se caracteriza por la caridad y la unidad.

La reivindicación polémica y enérgica de la cruz en los primeros capítulos de 1 Corintios pretende combatir la raíz de la que proceden las divisiones y disensiones que destrozan la comunidad. Los corintios valoran las expresiones religiosas según los criterios de la cultura helenística y, por eso, persiguen carismas espectaculares, se ufanan de la vinculación con un personaje prestigioso, sobrestiman la elocuencia. De aquí nacen las divisiones. La unidad y la caridad, que Pablo inculca a lo largo de toda la carta, surgen de la nueva valoración que tiene su punto de partida en Jesús Mesías crucificado: aprendemos a tener en más a los más débiles, a no buscar la ciencia que hincha, sino la caridad que edifica, a descubrir que la salvación no procede de la persona del predicador ni de sus dotes culturales, sino del hecho escandaloso del Mesías crucificado. Pero, paradojicamente, asi se abre un horizonte insospechado $(2,9)$, una sabidurla divina $(2,7)$ más profunda que la de este mundo.

En Gálatas, la imitación de Cristo crucificado $(5,24)$ es el fundamento de un comportamiento moral nuevo caracterizado por el amor mutuo y la unidad de la comunidad $(5,13-15)$.

El conocido himno de Filipenses 2, 6-11 con su referencia a la "muerte de cruz" (v. 8) se inserta en la carta precisamente para inculcar la unidad a los miembros de la comunidad, para que eviten las rivalidades $(2,14)$ y no busquen la vanagloria, sino la humildad, "considerando cada cual a los demás como superiores a sí mismo, buscando cada cual no su propio interés sino el de los demás" (2, 3-4).

El himno presenta el ejemplo de Cristo, partiendo de la gloria del preexistente y retomando a la gloria final del exaltado, para describir en el centro del texto la humildad de Cristo, que se humilló a sí mismo, llegando hasta el abajamiento máximo de la muerte de cruz.

2.3. La cruz era un patíbulo especialmente deshonroso y vergonzoso, que entraba en radical contraposición con el honor, que era el valor más estimable en la sociedad mediterránea del siglo $\mathrm{I}^{4}$. Por referencia especial al honor/vergüenza se pone de manifiesto para Pablo que predicar a Jesucristo crucificado es desafiar e invertir los valores más respetados de aquella sociedad.

El honor era la estima que una persona tenía a sus propios ojos y, sobre todo, a los de los demás, y se basaba en el lugar de origen, en la nobleza de su estirpe, Universidad Centroamericana José Simeón Cañas 
en su situación social y, eventualmente, en sus méritos personales. Obviamente para los judíos su conciencia étnica de pertenencia al pueblo elegido era su máximo honor. En una sociedad fuertemente patriarcal, el honor se simbolizaba en los órganos sexuales del varón y de la mujer, en su potencia, en el primer caso, y en su entrega exclusiva a su esposo y propietario, en el segundo. Por eso, el eunuco no tenfa honors y el adulterio de la mujer era la máxima deshonra. Así se explica también que para el varón judío su honor étnico se reflejase en su órgano sexual, mediante la circuncisión.

Estas sencillas consideraciones de antropología cultural se muestran extraordinariamente fecundas cuando se aplican a la lectura del Nuevo Testamento, pero aquí nos vamos a limitar a los textos referentes a la cruz. Numerosos testimonios de la época subrayan el carácter vergonzoso, infamante y deshonroso de la cruz. Se dice que los dioses inmortales de Grecia y Roma no tienen absolutamenle nada en común con la cruz, que es un signo de vergüenza (aiskhune. Cfr. Heb 12, 2). Se denomina a la cruz "estaca infamante" (infamis stipes), "leño desgraciado" (infelix lignum) y "madera criminal" (panourgikon xulon). ${ }^{6}$ Cicerón habla de "suplicio crudelísimo y espantoso" (crudelissimum taeterimumque supplicium) ${ }^{7}$. Celso pone en boca de los cristianos, para ridiculizar su [e, estas palabras: "Cree que quien yo te presento es el hijo de Dios, a pesar de los lazos deshonrosos y del suplicio vergonzoso (dedemenos atimotala $\hat{e}$ kekolasmenos aiskhisia) y a pesar de que ayer o anteayer se le haya tratado con la peor de las ignominias a los ojos de todos".

Las afirmaciones de Pablo sobre la cruz sólo se pueden entender a la luz de la realidad histórica de la cruz de Jesús y de la consideración cultural que este suplicio tenía. En las cartas paulinas es en el campo linguístico del honor y de la vergüenza donde preferentemente repercute la inversión de valores introducida por "la palabra de la cruz". En ICorintios, la cruz invierte el honor tal como se entendía en la cultura greco-romana. La prueba está, continúa Pablo, en que en la comunidad cristiana no hay muchos sabios, ni muchos poderosos, ni muchos de noble estirpe; al contrario, Dios eligió la necedad, la debilidad y lo innoble del mundo, lo despreciable y lo que no es para que nadie pueda alardear de honor (mê kaukhêsêsai) delante de Dios (1, 26-29).

En las cartas a los Filipenses y a los Gálatas, la cruz invierte el honor tal como lo entendían los judíos. En Filipenses previene contra la búsqueda del honor $(2,3)$, que es causa de divisiones en la comunidad, y exhorta a la humildad $(2,3)$, cuyo máximo ejemplo se encuentra en Cristo, que se hizo esclavo y llegó, incluso, a la ignominia de la muerte en cruz $(2,6-8)$. En Gálatas se encuentra la misma concatenación de ideas: quienes son de Cristo y participan de su cruz no andan detrás de la gloria vana $(5,24.26)$.

En Filipenses 3, 18-19 polemiza conera los judaizantes que quieren imponer la circuncisión a la comunidad y les dice que "ponen su gloria en su vergüenza Universidad Centroamericana José Simeón Cañas 
(aiskhune)", es decir, en su miembro circuncidado y, de esta forma, se convierten en "enemigos de la cruz de Cristo", que acaba con esta consideración judía del honor $e$ introduce una forma nueva de valorar la realidad.

Un planteamiento similar se encuentra en Gálatas 6, 12-15: los judaizantes que ponen su honor, ante todo, en su pertenencia étnica se glorían en la came y fuerzan a circuncidarse; así evitan ser perseguidos por la cruz de Cristo. Pero Pablo sólo pone su honor (kaukhèsthai) en la cruz de Cristo, que establece una contraposición con los valores establecidos en el mundo ("por la que el mundo está crucificado para mí y yo para el mundo"), y promueve una actitud novedosa ("ni la circuncisión es nada ni el prepucio, sino una nueva creatura").

En la carta a los Hebreos $12,1-4$ se exhorta a un comportamiento de resistentes, soportando la contradicción con el mundo. Para ello se invita a poner los ojos en Jesús, que soportó la cruz y arrostró la deshonra que (aiskhunes kataphronêsas) suponía, la máxima, dada la escala de valores de aquel mundo.

2.4. A la luz de la cruz interpreta Pablo su misma condición social como apóstol y las características de su predicación. Pablo reivindica polémicamente el personificar los valores alternativos de la cruz y se pone como ejemplo para sus comunidades. Personificar la cruz de Cristo sirve a Pablo para aumentar su autoridad.

En 1Corintios dice que "no quise saber entre ustedes sino a Jesucristo, y éste crucificado". La presencia del apóstol responde a la naturaleza de su mensaje: "me presenté ante ustedes débil, tímido y tembloroso" (2, 2-3). Lo mismo sucede con las características formales de su predicación: "mi palabra y mi predicación no tuvieron nada de los persuasivos discursos de la sabiduria" (2, 4).

Pablo afurma que la condición misma de la mayoria de los miembros de la comunidad de Corinto corresponde a esta inversión de valores introducida por la cruz: entre ellos no abundan los tenidos en el mundo por sabios, nobles o poderosos, sino los tenidos por necios, débiles y despreciables $(1,26-28)$. Pablo polemiza probablemente con una élite de la comunidad, a la que invita a descubrir, en la naturaleza misma de su grupo, la forma nueva de valorar la realidad que inaugura la cruz de Cristo.

Pero el apóstol hace más: esos "no-valores" según el mundo, que caracterizan a su comunidad, caracterizan a su propio ministerio. Sigue polemizando con la élite de la comunidad y se presenta como necio, débil y despreciable $(4,10)$, lo mismo que decía de la mayoria de la comunidad en 1, 27-28. En la composición sacial de la comunidad se refleja la necedad (môra), la debilidad (asthenê), lo sin honor (agenê: sin linaje) del mundo, lo despreciable y lo que no es (1, 27-28). De forma paralela, Pablo se presenta como necjo (móroi). débil Digitalizado por Biblioteca "P. Florentino Idoate, S.J.

Universidad Centroamericana José Simeón Cañas 
(astheneis) y sin honor $(4,10)$. Tanto al apóstol como a la comunidad se contrapone lo que el mundo (iene por sabio (sophous, phronimoi), fuerte (iskhura) y honorable (endoxoi).

Estas características del apóstol no se deben sólo a su falta de elocucncia, sino también a las persecuciones que sufre y al trabajo manual fatigoso y humillante, según la consideración de la cultura helenística. Es decir, es su situación real lo que lleva a Pablo a presentarse como personificación de los valores alternativos de la cruz. Por eso, en el mismo contexto, puede presentarsc como ejemplo a imitar por la comunidad de Corinto $(4,16)$.

En 2Corintios, Pablo defiende su apostolado contra los "supcrapóstoles" quc lo denigran y todo su planteamiento culmina identificándose con la debilidad del crucificado y con la fucrza de Dios $(13,3-4)$.

Dicen que su presencia es débil y su elocuencia despreciable $(10,10)$. Ha conocido persecuciones sin cuento $(11,23-26)$. Su trabajo manual le acarrea muchas penalidades $(11,27)$. Los "superapóstoles" ridiculizan su situación social y es que Pablo se humilló y renunció a vivir de la comunidad, porque quería predicar gratuitamente el evangelio $(11,7)$. Toda esta debilidad bien real, Pablo la relaciona con la de Cristo y se convierte paradójicamente en un reforzamiento de la legitimidad de su autoridad, hasta el punto de que sólo se gloría en su debilidad $(11,30 ; 12,5.9 .10)$, porque esto es lo que le identifica con Cristo crucificado. En efecto, Cristo fue crucificado en razón de su debilidad, de la que Pablo participa. Pero también en el apóstol, como en Cristo, se manifestará la fuerza de Dios sobre los corintios (13, 3-4; "cuando soy débil, entonces soy fuerte", decía en 12,10).

También en Gálatas Pablo reclama su identificación con Cristo crucificado. "Con Cristo estoy crucificado" $(2,19) ;$ "lejos de mí gloriarme si no en la cruz de nuestro Señor Jesús Mesías, por la cual el mundo está crucificado para mí y yo para el mundo" $(6,14)$. El apóstol no describe su situación de crucifixión con el detalle con que lo hace en 1 y 2 Corintios, pero parece claro que se refiere al conflicto, real y concreto, que sostiene con quienes intentan reintroducir la Ley y la circuncisión. Poco después dice, "llevo sobre mi cuerpo las señales (stigmata) de Jesús" $(6,17)$ : es muy probable que se esté refiriendo a las cicatrices de los malos tratos soportados por Cristo y que complete así la imagen de "su crucifixión".

\section{El resto del corpus paulino}

En las otras dos cartas auténticas de Pablo, 1Tesalonicenses y Romanos, no se menciona ni la cruz ni la crucifixión. En estas cartas, Pablo no tiene que defender su autoridad ni está en polémica. Hubiese sido especialmente duro mencionar la cruz a una comunidad recién convertida del paganismo, caso de

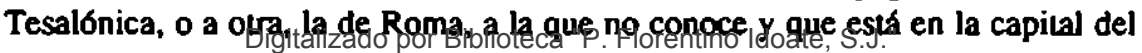


imperio.

En las carlas del Nuevo Testamento no atribuidas a Pablo no se menciona ni la cruz ni la crucifixión. Procedamos a un rápido examen de las referencias a la cruz en las cartas deuteropaulinas.

La gran construcción teológica de la carla a los Hebreos muestra una singular vinculación a la vida histórica de Jesús, sobre todo a su muerte. La cruz es citada una vez, en 12,2 . Se mantiene una conciencia muy clara de lo que históricamente era la cruz: un patibulo ignominioso $(12,2)$ y sangriento $(12,4)$.

La cruz de Jesús sirve para inculcar en los cristianos una actitud de contraposición y de resistencia frente a la sociedad. A la vez permite a la comunidad superar el conflicto y la persecución, viendo estas experiencias como análogas a las de Cristo?.

También hay referencias a la cruz en Efesos 2, 16 y Colosenses 1, 20 y 2 , 14. En ambas epístolas, la mención de la cruz se realiza para recordar la novedad de la situación religiosa introducida por Cristo. Estas carlas se encuentran, por tanto, en la línea paulina, pero hay una diferencia notable: se recuerdan la superación de la ley y de la circuncisión, pero esto ha dejado de ser ya un problema actual, y el contexto cs tcórico y no polémico. Se mantiene el recuerdo de la cruz, pero desprovisto del carácter socialmente conflictivo que tenía siempre en Pablo. Efesios y Colosenses son más epistolas generales que cartas concretas y reflejan el proceso de institucionalización y acomodación de la tradición paulina. En ambas epístolas la obra de reconciliación de Cristo, expresada ya en términos cósmicos, es el marco de una exhortación ardiente a la unidad en el seno de la comunidad.

En las cartas pastorales no hay ya ninguna referencia ni a la cruz ni a la crucifixión. A medida que la comunidad se institucionaliza y se acomoda al mundo se oculta el hecho escandaloso de la cruz, porque creaba enormes dificultades en las relaciones con la sociedad del imperio. La cruz tampoco era ya un principio hermenéutico válido para la comunidad. En efecto, (1) su identidad no pasaba por una contraposición social, sino por la aceptación de un "depósito" de verdades; (2) su moral era la del buen ciudadano, no una altemativa social; (3) la autoridad es legitimada legalmente (la transmisión y la imposición de las manos) y no había que recurrir a la identificación del líder con la debilidad del crucificado; (4) ni la composición social de la comunidad ni su situación social permitían encontrar homologías entre la comunidad y el crucificado.

\section{La cruz en los relatos evangélicos}

Fuera del relato de la pasion, las menciones de la cruz son muy escasas (Mc 8, 34 = Mt 16, 24 = Lc 9, 23: la cruz de los discípulos. El mismo tema en Mt 10,38 = Lc 14, 27. Texios propios de Mt: 20, 29; 23, 34; 26, 2). Los textos se Digitalizado por Biblioteca "P. Florentino Idoate, S.J." 
acumulan en la segunda parte del relato de la pasión y son de origen marcano. El cuadro siguiente recoge los usos de cruz y crucificar a parir de este momento.

\begin{tabular}{lccc}
\hline & Mc & Mt & Lc \\
\hline (1) Primera petición gente & 15,13 & 27,22 & 23,21 \\
(2) Segunda petición gente & 15,14 & 27,23 & 23,23 \\
(3) Decisión de Pilatos & 15,15 & 27,26 & - \\
(4) Jesús cond. por sold. & 15,20 & 27,31 & - \\
(5) Llevar la cruz & 15,21 & 27,32 & 23,26 \\
(6) Crucifixión & 15,24 & 27,35 & 23,33 \\
(7) Hora crucifixión & 15,25 & - & - \\
(8) Compafla de bandidos & 15,27 & 27,38 & - \\
(9) Burlas de la gente & 15,30 & 27,40 & - \\
(10) Burlas de los jefes & $15,32 \mathrm{a}$ & 27,42 & - \\
(11) Burlas de los bandidos & $15,32 \mathrm{~b}$ & 27,44 & - \\
\hline
\end{tabular}

Mateo recoge todos los texlos de Marcos excepto uno, quizá porque resulta una repetición innecesaria $(15,25 ;$ ifr. 15, 24). En cambio, en Lucas se percibe un claro deseo de eliminar las referencias, de las que deja sólo las imprescindibles, a pesar de que tiene todas las pericopas en las que aparece la cruz en Marcos. Es muy significativo que haya suprimido la decisión de Pilatos de crucificar a Jesús (Mc 15, 15). También elimina la cruz de todas las burlas (Mc 15, 30.32a.32b).

La conclusión es obvia: Lucas se dirige a una comunidad en pleno imperio romano y con un proyecto misionero, por lo cual la cruz le resulta especialmente molesta. Esta conclusión se ve confirmada por los datos de Hechos.

La cruz se menciona en el relato de forma escueta y no es directamente tcologizada, a diferencia de lo que sucede con los elementos que preceden y siguen a la muerte de Jesús

El relato más primitivo de la pasión namaba la crucifixión y mencionaba la cruz. La tendencia de la tradición no es a introducir menciones de la cruz, sino al contrario.

\section{La cruz en el kerigmo primitivo}

En las fómulas arcaicas del epistolario del Nuevo Testamento que reflejan el kerigma primitivo nunca se menciona la cruz ( $c f$. 1Cor 15, 3-5). También se he querido descubrir en los discursos de los Hechos rastros del kerigma primitivo. Esta predicacifon se formula de manema sumamente conflictiva con las autori- 
dades judias: "ustedes le mataron, pero Dios le resucitó...". Es notable que, mientras la muerte de Jcsús se cila rejteradamente, la cruz sólo se menciona dos veccs: 2,36 y 4,10. Parece que la primera predicación cristiana ha evilado llamar la atención sobre la cruz.

La mención expresa de la cruz (stawros) no se pone como cumplimiento de la Escritura, ni tampoco sc explicita su valor teológico. En cambio, ambas cosas suceden cuando se habla simplemente de la muerte de Jesús ("murió por nuesuros pecados, según las Escrituras", 1Cor 15, 3).

En Hechos 5, 30 y 10, 39 se alude a Deuteronomio 21, 23: "maldito de Dios todo el colgado del madcro"10. Se trata de textos de la predicación cristiana primitiva en los que se reivindica ante los judíos, de forma polémica y crítica, a Jesús, colgado del madero, pero resucilado por Dios. Probablemente nos encontramos con un eco de la primitiva apologética cristiana contra las objeciones judías al crucificado, que se basaban en Deuteronomio 21, 23".

En Gálatas 3, 13, Pablo cila explícilamente Deuteronomio 21, 23 también en un contexto polémico con el judaísmo. Poco antes, en 3, 1, se ha referido a la predicación de Jesucristo crucificado como un principio de innovación como hemos visto anteriormente-, de modo que la salvación no hay que buscarla ya en la Ley. Pero el apóstol continúa, argumentando al modo rabínico, para combatir a quienes desean imponer a la comunidad los usos judios y wdas las normas legales. Confiar en la ley es incurrir en la maldición, porque está escrito: "maldito (epikataratos) todo el que no permanece en todo lo escrito en el libro de la Ley cumpliéndolo" (Pablo cita Dt 27, 26). Pero Jesús nos ha librado de esta maldición, haciéndose él mismo maldición, porque está escrito: "maldito (epikataratos) todo cl que cuelga del madero" (ahora cita Dt 21, 33).

Es muy probable que estas fórmulas, que aluden inequívocamente a la cruz de Jcsús utilizando la terminología de Deuteronomio 21, 23, reflejen el kerigma cristiano primitivo en ambientc judío. De esta manera, la presentación de la cruz tiene una función social crítica e innovadora. Es notable que en estos textos se empieza a dar un valor salvílico a la muerte en cruz de Jesús.

\section{Reflexiones finales}

Litcrariamente hay un relato de la pasión, muy antiguo y de origen jerosolimilano, que mencionaba varias veces el hecho histórico de la cruz sin teologizarla expresamente. El dato de la cruz era innegable, pero la tadición tendió progresivamente a evilarlo.

En el uso plástico de la cruz observamos un fenómeno similar. Se dice frecuentemente que la cruz provocaba tal escándalo y dificultades en el imperio que no aparece hasta que, después de Constantino, los cristianos disfrutaron de

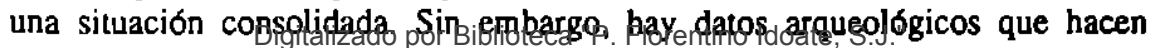


probable que las primeras comunidades judeocristianas palestinas ${ }^{12}$ así como también comunidades cerca de Roma (Herculano y Pompeya) ${ }^{13}$ ya usaron la cruz. La cucstión, cvidentemente, no es si se hicicron alusiones simbólicas a la cruz, que son indudables, sino si existieron referencias claras a su realidad histórica.

Una comunidad pobre, como cran las judeocristianas de Palestina, minoritaria y perseguida, conservaba, de forma fácil y natural, el recuerdo de la cruz de Jesús en su literatura y en sus representaciones. La cruz era una posibilidad real tambićn para cllos, cl crucificado era uno de los suyos, y la cruz era un símbolo preciso de su situación y de su relación con la sociedad.

Cuando la situación social de la comunidad cambia la cruz va entrando en contradicción con sus intercses sociales y su predicación disminuye (Lucas), sc hace genćrica (Efesios, Colosenses) y llega a desaparecer (pastorales). Los reproches cle Celso (C. Cel. Vl, 10) y el dibujo burlesco del asno crucificado del Palatino demuesuran el cscándalo y la dificultad que suponía la cruz. Del arte se eliminan el resrato humano de Jesús y la cruz, que no volverá reaparecer hasta el siglo IV. En varios apologetas, preocupados por legitimar y hacer relevante el cristianismo en la cultura del ticmpo, desaparecen las menciones a la vida histórica y a la muerte de Jesús (Atenágoras, Taciano, Teófilo, Minucio Félix, el recopilador de las Sentencias de Scxtus).

Consuntino abolió la pena de la crucifixión, precisamente porque su fe cristiana le hacía recordar lo sucedido a Jesús. A partir de este momento, la cruz reaparccerá convertida en un simbolo triunfal, que se encontrará en el cuello de los fieles, en lo más alto de las basílicas, en las monedas, en las habitaciones privadas, en la diadema y en el cetro imperial; ya no entorpece las relaciones con la sociedad. Pero este proceso no fue repentino y contó con dificultades. Es interesante que Eusebio de Cesarea, en su Vita Consiantini, al describir la basílica del Santo Sepulcro sólo hable de la tumba, el lugar de la resurrección, y no mencionc para nada el Gólgota y la cruz. Es un dato que no podía ignorar, porque cl lugar del calvario era conocido y venerado y, además, en la basílica se vencraba la cru\%, que se consideraba recién descubierta. Su silencio se debe, probablementc, a la visión triunfalista que quiere presentar del cristianismo ${ }^{14}$.

En la medida en que la cruz manciene sus connotaciones históricas, las funciones sociales de su predicación tienen un sentido muy coherente y preciso. La cruz se rcivindica polémicamente para acentuar la novedad de la salvación cristiana. U. Luz afirma que "los dos grandes leólogos de la cruz del Nuevo Testamento, Pablo y Marcos, son tcólogos polémicos"ls. Y añade que su teología dc la cruz no es una contraposición con judíos o con paganos, sino con otras tcologías cristianas. Más tarde dicc:

Una teología de la cruz, en el sentido propio de la palabra, no es algo obvio

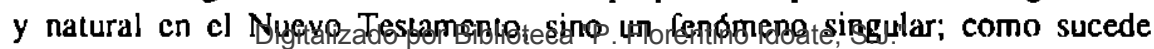
Universidad Centroamericana José Simeón Cañas 
siempre en la historia de la Iglesia cuando imumpe una teologia de la cruz crítica de la teología misma ${ }^{16}$.

E. Käsemann subrayó, con su fuerza caracteristica, el carácter polémico de una auténtica teología de la cruz:

La expresión teología de la cruz si se usa de forma no polémica pierde su sentido original. Siempre se ha afirmado críticamente contra una interpretación del mensaje cristiano dominante en la tradición y no es casualidad que haya caracterizado la reacción protestante" ${ }^{17}$.

El mismo autor es muy consciente de que la predicación paulina de la cruz sólo puede entenderse si se parte de la consideración que históricamente tenía la cruz:

La cruz, que es hoy símbolo de religiosidad, era expresión de la lejania de Dios y, por eso, la veneración del que en ella colgaba resultaba un escándalo... La consideración edificante (Erbaulichkeit) de la cruz obstaculiza al evangelio más que la desmitologización, porque inmuniza contra la sacudida brutal del mensaje de Cristo y nos sumerge en un mundo de consideraciones razonables $y$ banales ${ }^{10}$.

Kasemann también seffala que la teología de la cruz se abría paso históricamente de forma polémica con otras teologias y espiritualidades cristianas:

La teologia paulina (de la cruz) dirige sus ataques no principalmente contra personas poco consideradas desde el punto de vista religioso o tenidas por inmorales... Los enemigos de Cristo en Galacia y en Corintio, en Filipo y en Roma... se encuentran entre los miembros más celosos y piadosos de las comunidades $^{19}$.

La predicación de la cruz expresa también la originalidad de sus contenidos morales. La cruz funda la identidad del propio grupo en contraposición a la sociedad y según unos valores radicalmente alternativos a los vigentes en ella.

La cruz ofrece una fuente de legitimidad de la autoridad contrapuesta a las de la cultura judía o helenistica.

La cruz da sentido a la existencia perseguida de la comunidad cristiana.

El binomio muente-resurrección es mucho más plurifuncional que el de crucifixión-resurrección. La cruz es lo más contingente, conflictivo y escandaloso de la historia de Jesús. La Iglesia está siempre tentada o a dejar de hablar de la cruz (no de la muerte de Jesús) o a metaforizarla para diluir su sentido histórico y modificar sus funciones sociales, esencialmente molestas desde el punto de vista instibucional.

V. W. Turner ${ }^{20}$ ha estudiado los rilos de inversión de estado y de elevación de esiado, que coinciden en presentar un periodo liminal, es decir, un momento 
de paso, en que no se poseen los atributos ni del estado pasado ni del venidero. Este autor relaciona el proceso ritual con la estructura social.

Quizá se puede comparar la crucifixión con el período liminal o de paso, que se descubre en ambos rituales. No me refiero a la representación ritual, tan importante, de la muerte de Jesús en el culto, sino a la presencia de la cruz en la predicación. Y me limito a una breve sugerencia.

La presentación de la crucifixión guarda, a veces, cierta analogía con la liminalidad de los rituales de elevación de estado, en los que se somete al neofito a una serie de humillaciones que preceden a su elevación estructural. Como la liminalidad de las crisis vilales, puede compararse a la tragedia, que implica humillaciones, desgarramientos y dolor. En ouras ocasiones, la presentación de la crucifixión guarda analogía con los rituales de inversión de estado. Es el caso cuando el estrucluralmente inferior, por medio de una conducta extravagante, se hace superior. Es una forma de reaccionar contra la degradación de la estructura social y de reivindicar los valores de la communitas. La liminalidad de la inversión de estado puede compararse a la comedia, pues ambas se caracterizan por la burla y la inversión de las reglas estructurales (Turner dice que no implica la destrucción de estas reglas).

No es ninguna casualidad que los esıudios modemos de los relatos evangéli$\cos$, que subrayan su carácter narrativo y su trama esencialmente conflictiva y que desemboca en la cruz, pongan de manifiesto su analogía con la tragedia y con la comedia'?

\section{Notas}

1. The Social Context of Pauline Theology, Interpretasion 36 (1982) 266-277.

2. Sociology and the New Testamens, Minneapolis 1990, 138-139.

3. Cruz/stauros aparece en Mc 8, 34 (Mt 16, 24; Le 9, 23); 15, 21 (Mt 27, 32; Lc 23. 26); 15, 30 (Mt 27, 40); 15, 32 (Mı 27, 42); en Q: Mı 10, 38 (Lc 14, 27). En In 19. 17. 19. 25. 31 . En el corpus paulino: 1 Cor $1,17.18$; Gal 5, 11; 6, 12. 14; Fil 2. 8; 3 . 18; Ef 2, 16; Col 1, 20; 2, 14; Heb 12, 2.

El verbo crucificar/slaurô aparece en Mc 15, 13 (Mt 27, 22; Lc 23, 21); 15. 14 (Mt 27, 23; Lc 23, 23); 15, 25 (Mt 27, 26); 15, 20 (Mt 27, 31); 15, 24 (Mt 27, 35; Lc 23. 33); 15, 25; 15, 27 (Mt 27, 38); 16, 6 (MI 28, 5); MI 20, 19; 23, 34; 26, 2; Lc 24. 7. 20. En In 19, 6a. 6b. 10. 15a. 15b. 16. 18. 20. 23. 41. En Hechos: 2. 36; 4, 10. En el corpus paulino: 1 Cor $1,13.23 ; 2,2.8$; 2 Cor 13,4 ; Gal 3,$1 ; 5,24 ; 6,14$; Apoc 11 , 8. El compuesto anastauroo, crucificar de nuevo, aparece en Heb 6,6. Y sunstauroô, crucificar con, en Mc 15, 32 (Mt 27, 44); Jn 19, 32; Rom 6, 6; Gal 2. 19.

4 B. J. Malina, The New Testament World: Insights from Cultural Anthropology, Allanta 1981. 
5. J. Jeremias, Jerusalen en tiempos de Jesús, Madrid 1977, 353 s.

6. Séneca, Epistolae morales 101. 14.

7. Contra Verros 2. 5. 165.

8. Origenes, Consra Celso, VI, 10.

9. En los primeros testimonios cristimos aparecen unides la realidad de los sufrimientos y muerte de Cristo con la acepención del martirio. Los gnosticos se oponfan a] martirio porque decían que no suponín ninguna imilación real de Cristo, ya que el sufrimiento de éste no afectaba a su realidad trascendente. Tettuliano (De Anima 55) siáa el comienzo de la herejía gnóstica en las persecuciones, como un medio teológico de los creyentes cobardes para justificar su comportamiento. En los escritos de Nag Hammadi se ve que entre los gnósticos había diversas posturas ante el martirio. Pero una cosa aparece con claridad: que la interpretación de la pasión de Cristo se corresponde con su actitud ante el martirio. Cfr. E. H. Pagels, Gnostic and Orthodox Views of Christ's Passion: Paradigms for the Christian's Response to Persecution?, en The Rediscovery of Gnosticism. Proceedings of the Conference at Yale. March 1978. I. The School of Valentinus, E. Laylon (ed.), Leiden 1980.

10. Dr 21, 23 en los LXX: kekateraménas hupo Thou pas tremómenos epi xulou. Heh 5. 30. kremasantes epi xúlou. Hch 10, 39: kremésantes epi xúlou. Véase también Hch 13, 29.

11. En el Dib́logo de Trifón (XXX) de Justino se pone este reproche contra la fe cristiana en boca del judío Trifón.

12. B. Bagarti - J. T. Milik, Gli Scavi del Dominus Flevis. Parte I. La Necropoli del Periodo Romano. Gerusalemme 1958, sostienen que en el cementerio del Dominus Fevit, en el monte de los Olivos, que dala del siglo I-II, se encuentran sarcófagos judeocristianos con el signo de la cruz. El arqueólogo judío C. D. Sukenik deljende que la cruz se encuentra en unos sarcofagos cristimos encontrados en el barrio de Talpiot, en la ciudad de Jerusalén, y que data de poco despues del ano 40: The Earliest Records of Christianiry, American Journal of Archeology 51 (1947) 351-365. A. Niccaci, en un estudio panoránico sobre los recientes descutrimientos aqueológicos en Palestina que pueden interesar al Nuevo Testamento, afirma lo siguiente: "Se lee, por ejemplo, que los cristianos antiguos se opusieron a hacer de la cruz el símbolo de su fe, debido a la incompresión que provocaba tanto en el mundo hebreo como en el pagano. Sin embargo, el símbolo de la cruz se encuentra lestimoniado ya en una época antiquísima, ciertamente antes de Constantino, como se ve por los descubrimientos arqueológicos": L'ambiente del Nuovo Tessamento $e$ della chiesa primitiva alla luce degli seavi dello Studium Biblicum Franciscanum (Gerusalemme), Antonianum LVII (1983) 38.

13. L. W. Barnard, The Cross of Herculanewn Reconsidered, en W. C. Weinrich (ed.), The New Testament Age. Essays in honor of B. Reicke. Vol. I., Macon 1984, 14-27.

14. Segun Ze ev Rubin. The Church of the Holy Sepulcre and the Conflict between the Sees of Caesarea and Jerusalem, en De Jerusalem Cashedra, n. 2, 1982, 79-105. Eusebio, obispo de Cesarea, no habla de la cruz por su rivalidad con Macario, obispo de Jenusalén, que es quien la ha descubierto junto con Santa Elena. En mi opinión hay que dar más importancia a la visión triunfalista del cristianismo, que está en el origen del enfasis de Eusebio en la resurrección y en su silencio sobre la cruz. En Laudes Consartini Eusebio hace uns ligera mención a la cruz como "signo salvador". sin referencia específica al dato historico del patibulo de Jesús, en Digitalizado por Biblioteca "P. Florentino Idoate, S.J."

Universidad Centroamericana José Simeón Cañas 
conexión con la basilica constantiniana de Jerusalén, pero sólo después de haberla mencionado como signo de vicloria sobre los enemigos del emperador y sobre los paganos. A partir de entonces, la cruz es introducida en todas las iglesias construidas por el emperador. Sobre la ideología imperial subyacente a la obra de Euscbio puede verse: E. Hoornacr, "Eusebio de Cesarea y la historia de la Iglesia. Para una hiscoria de la Iglesia a partir de los pobres", Revista Latinoamericana de Teología II (1985) 185-194.

15. Theologia crucis als Mille der Theologie im Neuen Testamen, Evangelische Theologie 34 (1974) 118.

16. Art. c., 120.

17. "Die Heilsbedeutung des Todes Jesu bei Paulus", en Paulinische Perspekiven, Tübingen 1972, 67.

18. O. . ., 69.

19. O.c. 72 .

20. El proceso ritual, Madrid 1988,

21. D. E. Aune, New Testament in /ss Literary Environment, Philadelphia 1987. 